\title{
Evaluation of Stay-Green Sorghum Germplasm Lines at ICRISAT
}

\author{
Viswanathan Mahalakshmi* and Francis R. Bidinger
}

\begin{abstract}
Delaying leaf senescence is an effective strategy for increasing cereal production, particularly under water-limited conditions. A set of 72 nonsenescent (stay green) genotypes of sorghum [Sorghum bicolor (L.) Moench] was evaluated for pattern of postflowering leaf senescence in replicated field experiments during the 1998-1999 and 1999-2000 post-rainy seasons at the International Crops Research Institute for Semi-Arid Tropics to identify superior sources of stay green. Individual leaves of three plants per plot were scored visually for leaf senescence at weekly intervals from flowering until harvest maturity. Leaf senescence patterns were determined by fitting logistic or linear functions to weekly percent green leaf area (\% GLA), from which \% GLA at 15, 30, and $45 \mathrm{~d}$ after flowering were estimated. On the basis of estimated \% GLA at 15, 30, and $45 \mathrm{~d}$ after flowering in the two years, genotypes clustered into five groups. The clusters retained $74 \%$ of the total variation in \% GLA, despite differences in the pattern of development of stress and subsequent leaf senescence pattern between the two years. Cluster 1 genotypes, which combined nonsenescence with drought escape, through early flowering, were superior to Cluster 2 genotypes, which were nonsenescent but late flowering, in the more severely stressed year when drought escape was important, but not in the milder stress year when escape was less of a factor. The experiment identified several (e.g., IS 22380, QL 27, QL 10, E36 $\times \mathbf{R} 16$ 8/1) tropically adapted lines with stay-green expression equivalent to those of the best temperate lines B 35 and KS 19.
\end{abstract}

A NUMBER OF ANNUAL CEREALS exhibit genetic variation for the degree or rate of leaf senescence during grain filling (Thomas and Smart, 1993). Delayed senescence (or stay green) in sorghum is considered a valuable trait, as it improves genotype adaptation to postflowering drought stress, particularly in environments in which the crop depends largely on stored soil moisture to fill and mature grain (Rosenow et al., 1977). Specifically, stay green has been associated with reduced lodging (Mughogho and Pande, 1984), lower susceptibility to charcoal rot [caused by Macrophominia phaseolina (Tassi) Goid.] (Mughogho and Pande, 1984), higher levels of stem carbohydrates both during and after grain filling (McBee, 1984), and improved grain filling and grain yield under stress (Rosenow and Clark, 1981). Because of these benefits, selection for enhanced stay green has been an important component of breeding for improved drought tolerance and improved grain yield in breeding programs in the USA (Rosenow et al., 1983) and Australia (Henzell et al., 1992) for many years.

Recent research has provided a better understanding of the genetics and the physiology of stay green. Greater green-leaf-area duration during grain filling appears to

International Crops Research Institute for the Semi Arid Tropics (ICRISAT), Patancheru 502324, Andhra Pradesh, India. Received 23 March 2001. *Corresponding author (V.MAHALAKSHMI@ CGIAR.ORG).

Published in Crop Sci. 42:965-974 (2002) be a product of different combinations of three distinct factors: green leaf area at flowering, time of onset of senescence, and subsequent rate of senescence (van Oosterom et al., 1996; Borrell et al., 2000a). Further, all three factors appear to be inherited independently (Van Oosterom et al., 1996), and thus sources expressing different components can be combined easily in breeding programs (Borrell et al., 2000a). Stay-green hybrids have been shown to produce significantly greater total biomass after anthesis, to retain greater stem carbohydrate reserves, to maintain greater grain growth rates, and to have significantly greater grain yields under terminal drought stress than related but senescent hybrids (Borrell et al., 1999, 2000b). Stay-green genotypes also appear to have higher leaf-nitrogen concentrations (specific leaf nitrogen) at flowering and maintain these during grain filling (Borrell and Hammer, 2000), which is possibly associated with a higher transpiration efficiency in the best stay-green hybrid (Borrell et al., 2000c).

Conventional breeding for stay green has been based primarily on two sources for this trait, B 35 and KS 19. KS 19 is a selection from a cross of short Kaura, an improved landrace cultivar from northern Nigeria, with Combine Kafir 60 (Henzell et al., 1984). B 35 (PI 534133) was selected from a converted (dwarf height, early flowering) version of IS 12555, an Ethiopian landrace (Rosenow et al., 1983, 1996). KS 19 has been used commercially primarily in the breeding program of Queensland Department of Primary Industries, whereas B 35 is widely used in both public and private sector breeding programs in the USA. Recent research suggests that the two sources differ in the mechanisms by which they prolong leaf-area duration during grain filling. Both sources delay the onset of senescence. They differ in that B 35-derived lines have a greater leaf area at flowering and a normal rate of leaf senescence, whereas KS 19-derived lines have a smaller leaf area at flowering and a slower rate of leaf senescence (Borrell et al., 2000a).

Although the ability of leaves to delay senescence has a genetic basis in sorghum (van Oosterom et al., 1996), the expression of the character is strongly influenced by environmental factors. The trait expresses best in environments in which the crop is dependant upon stored soil moisture, but where this is sufficient to meet only a part of the transpiration demand. Sufficient expression of the trait for selection is thus dependant upon the occurrence of a prolonged period of drought stress during the grain-filling period of sufficient severity to accelerate normal leaf senescence, but not of sufficient magnitude to cause premature death of the plants. Because of this precise requirement for the trait expression, field environments do not offer ideal conditions for selection and molecular markers associated with this trait

Abbreviations: \% GLA, percent green leaf area; DAF, days after flowering; DAS, days after sowing. 
may offer the better alternative (Crasta et al., 1999; Xu et al., 2000).

The limited number of sources of stay green currently in use in sorghum breeding programs contrasts with its importance in improving adaptation to postflowering drought stress, and with the effort being invested in identifying molecular markers to transfer it to new lines more effectively. A search for additional sources of stay green, which may be different genetically or physiologically, would thus be worthwhile. The objective of the research reported in this paper was to evaluate critically a number of stay-green sources available at ICRISAT for their patterns of leaf senescence under terminal stress conditions.

\section{MATERIALS AND METHODS}

\section{Genetic Materials}

On the basis of earlier research conducted at ICRISAT, a number of stay-green lines were identified from the ICRISAT sorghum-breeding program. Additional lines were furnished by collaborators in Australia and the USA for evaluation in the post-rainy (stored moisture condition)-season environment. These lines are listed in Table 1, along with their pedigrees, where known. A total of 81 lines was evaluated during the post-rainy season of 1998, of which only 72 flowered in a reasonable period of time $(<95 \mathrm{~d})$. These 72 lines were reevaluated during the post-rainy season in 1999. B 35 was included as a check, as it is the most widely used stay-green source in breeding programs in the USA and Australia, and it expresses the trait well in the post-rainy season in India (authors, unpublished data).

\section{Field Experiments}

The experiments were conducted during the post-rainy seasons (October to February) of 1998-1999 and 1999-2000 at ICRISAT, Patancheru $\left(17^{\circ} 30^{\prime} \mathrm{N}, 78^{\circ} 16^{\prime} \mathrm{E}\right.$, altitude $\left.545 \mathrm{~m}\right)$. This season is ideal for evaluating the expression of adaptive traits for terminal moisture-deficit conditions, as the crop is dependant entirely on stored soil moisture and undergoes a long, progressive stress under moderate evaporative demand conditions (Sivakumar et al., 1979). Severity and time of onset of stress can be manipulated by a choice of soil texture and/ or depth to vary total plant-available water content, and onset of stress can be further manipulated (on shallow soils) by refilling the profile at varying times prior to flowering. The experiments reported here were planted on a shallow $(40-60 \mathrm{~cm})$ vertic inceptisol (very fine montmorillontic isohyperthermic) overlying a loose, decomposing granite-base material that is permeable to roots but contains limited plant-available water.

In the 1998-1999 experiment, the 81 genotypes were arranged in a $9 \times 9$ lattice design with four replications. In the 1999-2000 experiment, 72 of the original 81 genotypes were arranged in a 9 (genotypes per block) $\times 8$ (blocks per rep) alpha design, with three replications. The 1998-1999 experiment was planted on 10 November in 3-row plots, each row $4 \mathrm{~m}$ long and spaced $0.60 \mathrm{~m}$ apart. The 1999-2000 the experiment was planted on 21 October in 2-rows plots, each row $4 \mathrm{~m}$ long and $0.60 \mathrm{~m}$ apart. A basal application of $20 \mathrm{~kg} \mathrm{ha}^{-1}$ $\mathrm{N}$ and $20 \mathrm{~kg} \mathrm{ha}^{-1} \mathrm{P}_{2} \mathrm{O}_{5}$ as di-ammonium phosphate was banded before sowing. The seeds were machine planted and the field irrigated with overhead sprinklers to ensure germination. The crop was thinned $10 \mathrm{~d}$ after emergence to about 60000 plants $\mathrm{ha}^{-1}$. Twenty days after emergence, an additional $45 \mathrm{~kg} \mathrm{ha}^{-1}$
$\mathrm{N}$, as urea, was side-dressed and the field given a light (15 $\mathrm{mm}$ ) sprinkler irrigation. Flowering was recorded as the time of stigma emergence in $50 \%$ of the main-shoot panicles. At maturity (about $60 \mathrm{~d}$ after flowering), panicles from one meter of the central row (1998-1999), or from two meters of both rows (1999-2000),were harvested, dried, and threshed to estimate grain yield. The crop was protected from both leaf feeding insect pests and stem borers with appropriate insecticides. Regular prophylactic measures were taken to prevent leaf rust, which is common during this season.

\section{Estimation of Senescence}

At the time of emergence of the flag leaf, three uniform plants in each plot were tagged, the length and breadth of upper six leaves measured, and the area of each estimated as: leaf length $\times$ leaf width $\times 0.70$. (This factor was determined by measuring the leaf length, breadth, and actual area of 50 randomly chosen leaves.) Beginning at flag leaf emergence, the percentage remaining green of each of the upper six leaves of each tagged plant was visually estimated at weekly intervals, on a linear 0 -to- 9 scale, where $0=0$ to $10 \%$ green-leaf area, and $9=90$ to $100 \%$ green-leaf area. Weekly green-leaf area of each tagged plant was calculated by multiplying the percent green-leaf area by the measured area of each leaf, and summing across the six measured leaves. Percentage green-leaf area (\% GLA) for each plant, for each week, was calculated by dividing the estimated GLA for that week by its measured leaf area at flowering. Plot values for\% GLA were calculated by averaging the individual plant values for each plot.

The weekly \% GLA data were used to fit an appropriate equation to describe the pattern of leaf senescence during the period of observations; -6 to $+55 \mathrm{~d}$ after flowering (DAF) in 1998 , and -10 to +55 DAF in 1999-2000. For the 19981999 data, a logistic fit was satisfactory $\left(R^{2}>90 \%\right)$ for majority of the plots. For those where logistic equation did not provide a satisfactory fit, a second order polynomial fit was used. For the 1999-2000 data linear fits were satisfactory for most plots, for those where a linear fit was not adequate, a second order or logistic fit was used. In both years, the coefficient of determination for all plots were not less than $90 \%$. In both years, the fitted equation for each individual plot was used to estimate \% GLA at 15, 30, and 45 DAF. These estimated values were used in the analysis of genotype differences in stay green and in the clustering of genotypes.

\section{Data Analysis}

Nine entries in the experiment in 1998-1999 that failed to flower in a reasonable time were excluded from the analysis, and the data for the 72 remaining genotypes were analyzed as an unbalanced lattice by means of REML option of GENSTAT (ver. 5.5). The 1999-2000 data were analyzed by the same program, with all effects, including genotype, considered as random. The data for the two years were combined and reanalyzed to partition variances into genotype, year, and genotype $\times$ year effects and to calculate heritabilities for the expression of stay-green trait at various times after flowering, by the REML option of GENSTAT. Genotype data reported in all tables and figures are the Best Linear Unbiased Predictors (BLUP) of genotype means.

To separate the 72 genotypes into groups on the basis of their stay-green expression at various times after flowering, cluster analysis (Wards method) on standardized data (SAS Inst., 1996) was done using six variables: \% GLA at 15, 30, and $45 \mathrm{DAF}$ from both the years. Clustering based on individual year's data takes into account the differences in leaf-senescence patterns in the two years. 


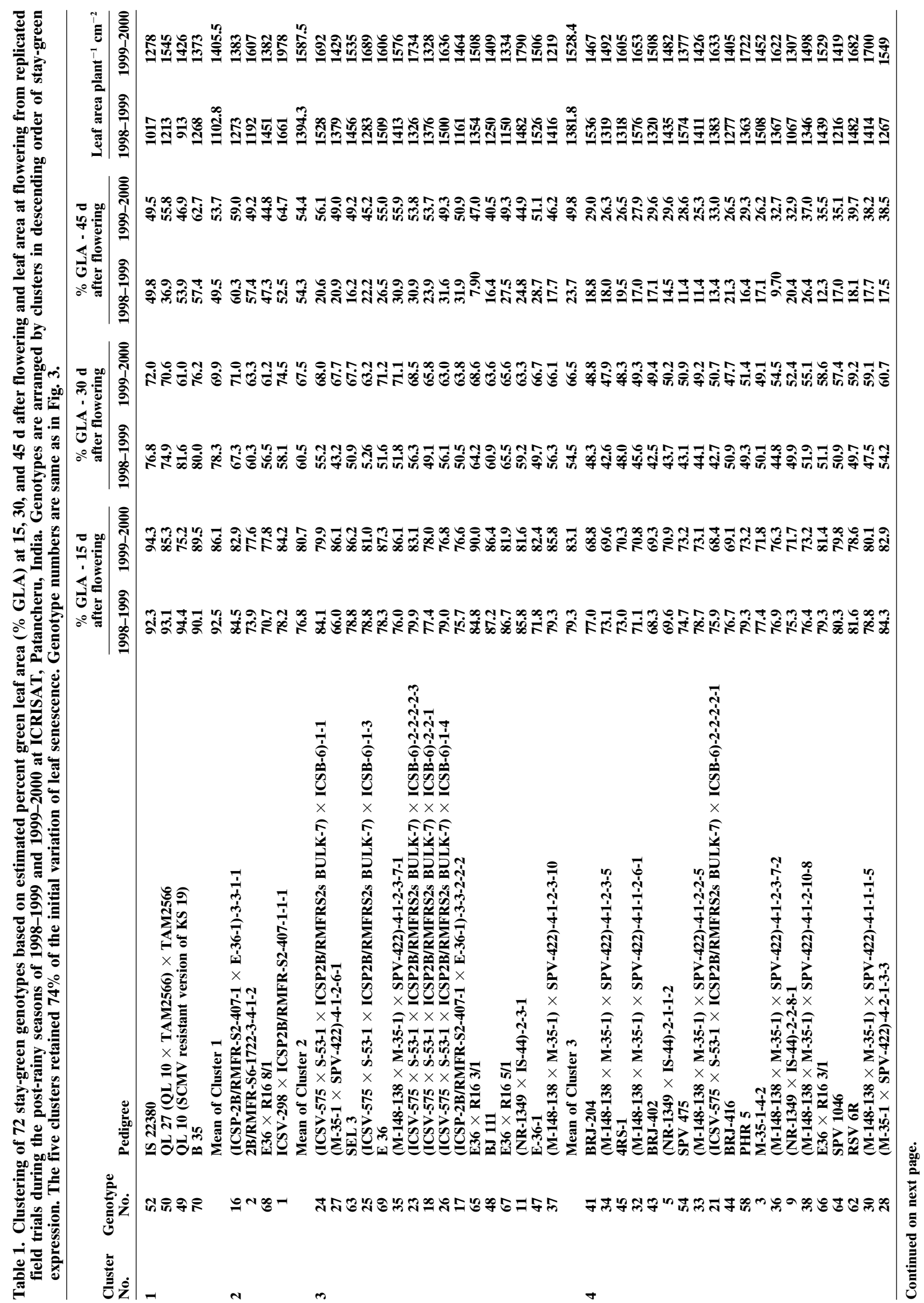




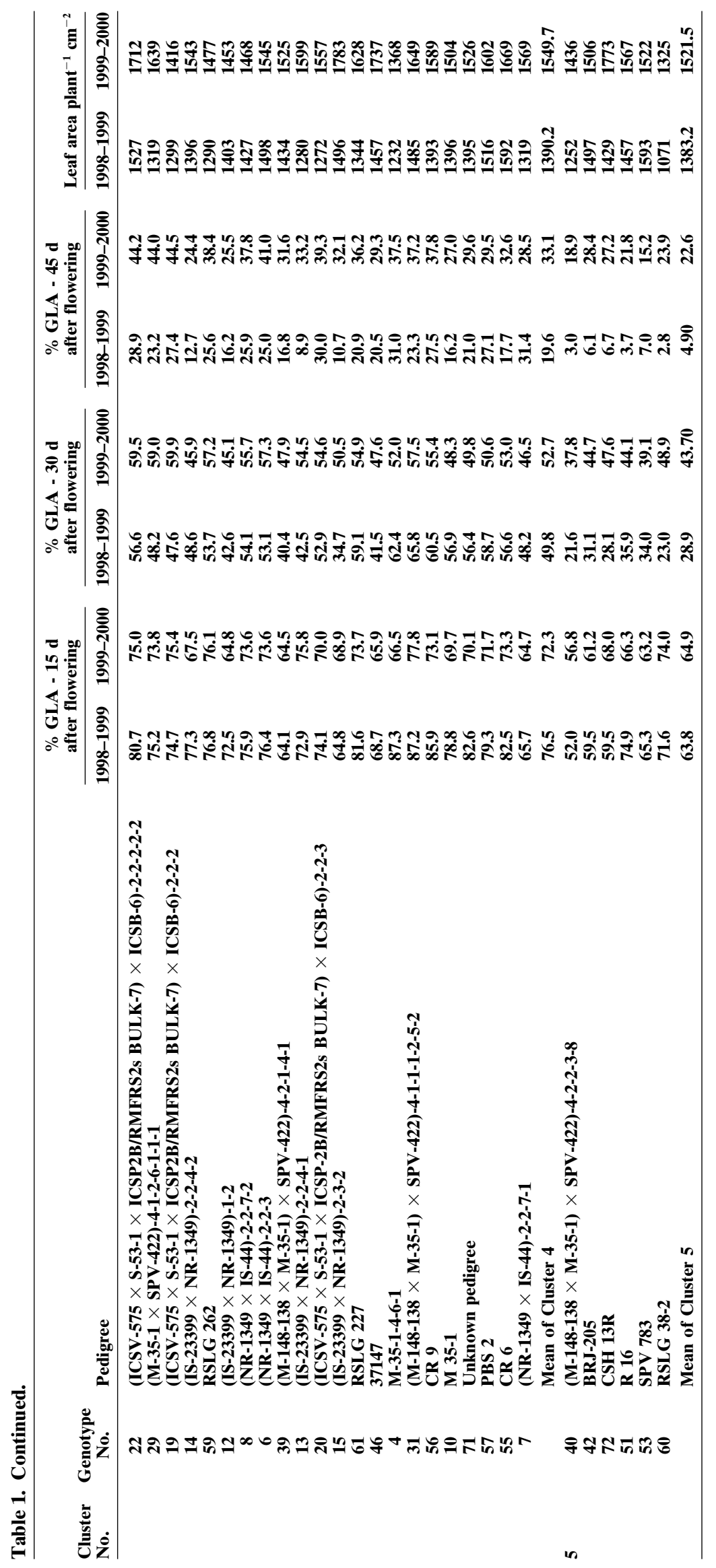




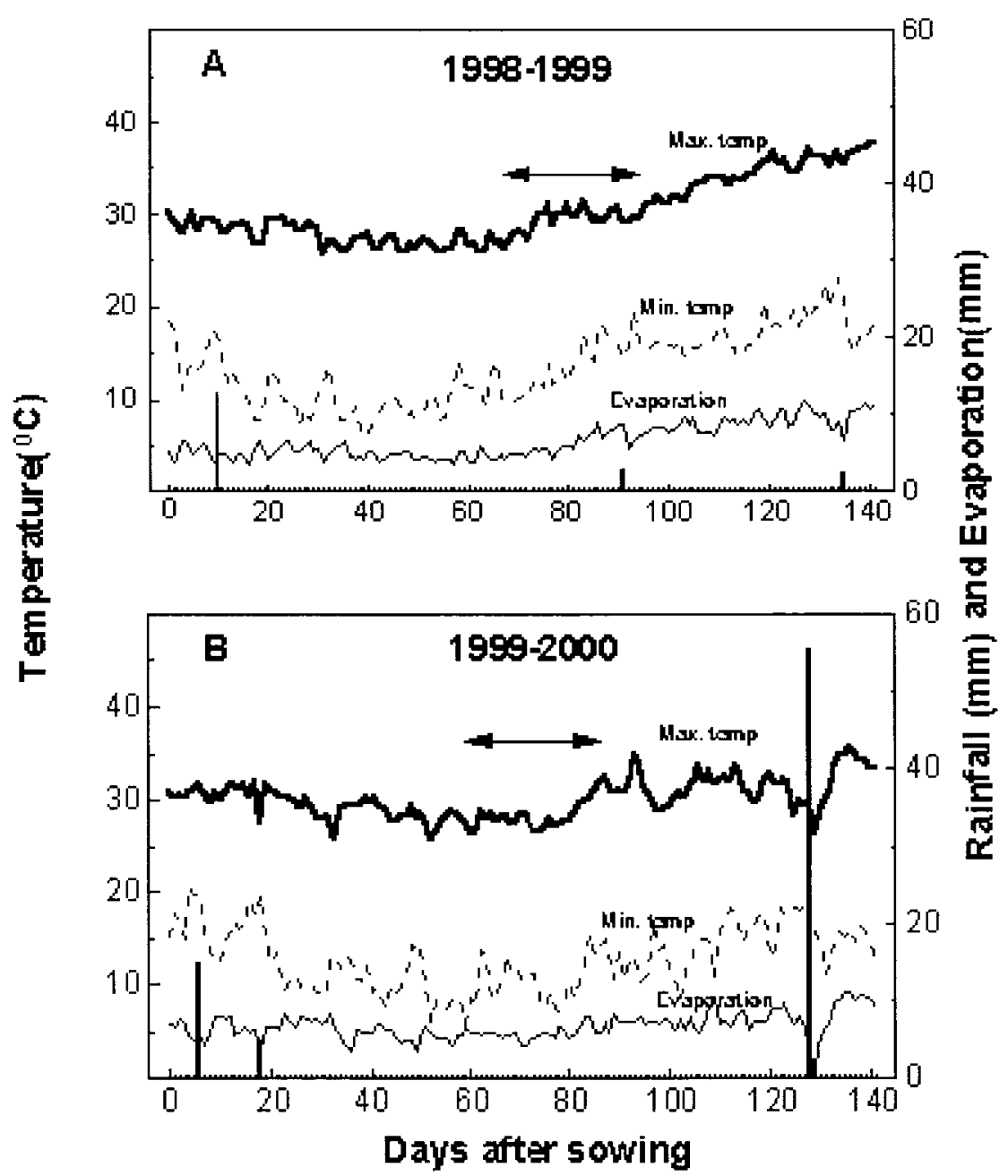

Fig. 1. Maximum and minimum temperatures, rainfall (vertical bars), and pan evaporation during the field evaluation of 72 stay-green sources during the post-rainy seasons of 1998-1999 (A) and 1999-2000 (B) at ICRISAT, Patancheru, India. The horizontal arrow indicates the range in flowering time in each year.

\section{RESULTS AND DISCUSSION Crop Growth and Yield}

The postflowering atmospheric stress was greater in 1998-1999 than that in 1999-2000, partly because of the later (20 d) planting date, and, consequently later (15 d) mean flowering date in the first year. Cumulative Class A pan evaporation for 1998-1999 was $96 \mathrm{~mm}$ for the period from the mean flowering date to $15 \mathrm{DAF}, 103$ $\mathrm{mm}$ for 16 to $30 \mathrm{DAF}$, and $119 \mathrm{~mm}$ for 31 to $45 \mathrm{DAF}$; for a total of 318 for the entire period from flowering to maturity. The corresponding figures for 1999-2000 were 82,90 , and $96 \mathrm{~mm}$, for a total of $268 \mathrm{~mm}$. There was an isolated, but heavy rain storm $(55 \mathrm{~mm})$ during the later part of grain filling (129 DAS or between 44 DAF for latest flowering genotype and 69 DAF for earliest flowering genotype) in 1999-2000 (Fig. 1), when all genotypes were at or past maturity and the \% GLA was estimated only until $45 \mathrm{DAF}$, and the crop lodged.

The mean time to flowering was $5 \mathrm{~d}$ earlier in 19992000 (74 d) than in 1998-1999 (79 d). This appeared to be an effect of somewhat cooler preflowering temperatures in 1998-1999 than in 1999-2000, as heat units (on the basis of $10^{\circ} \mathrm{C}$ ) accumulated from sowing to mean flowering time were similar in the two years $\left(742^{\circ}\right.$ days in $1998-1999$ and $777^{\circ} \mathrm{C}$ days in 1999-2000). The range in time to flowering among the genotypes was about $25 \mathrm{~d}$ in both years (71 to $95 \mathrm{~d}$ in 1998-1999 and 60 to $85 \mathrm{~d}$ in 1999-2000). Genotype and genotype $\times$ year differences in time to flowering were highly significant (Table 2). Preflowering growth was better in 1999-2000, despite the fact that the mean preflowering growth period was $5 \mathrm{~d}$ shorter than in 1998-1999, possibly because of the warmer preflowering temperatures. Mean leaf area per plant at flowering (the measured upper six leaves) was $1372 \mathrm{~cm}^{2}$ (range: $913-1661 \mathrm{~cm}^{2}$ ) in 1998-1999 vs. $1536 \mathrm{~cm}^{2}$ (range: $1219-1978 \mathrm{~cm}^{2}$ ) in 1999-2000. Genotype and genotype $\times$ year effects for leaf area at flowering were significant (Table 2). In both the years, leaf area at flowering was not related to time to flowering $(r=0.15, P>0.19$; and $0.12, P>0.33)$, suggesting that inherent differences in leaf size and leaf area among genotypes that was not influenced by the time to flowering.

The mean grain yield was $121 \mathrm{~g} \mathrm{~m}^{-2}$ in 1998-1999 (range from $65-161 \mathrm{~g} \mathrm{~m}^{-2}$ ) and $215 \mathrm{~g} \mathrm{~m}^{-2}$ in 19992000 (range from 110-327 $\mathrm{g} \mathrm{m}^{-2}$ ). Differences among 
Table 2. Analysis of variance and heritabilities for percentage green leaf area (\% GLA) at 15,30 , and 45 d after flowering (DAF), green leaf area (GLA) at flowering and days to flowering from the field experiments conducted during the post-rainy seasons of 1998-1999 and 1999-2000 at ICRISAT, Patancheru, India.

\begin{tabular}{|c|c|c|c|c|c|c|}
\hline \multirow[b]{2}{*}{ Source of Variation } & \multirow[b]{2}{*}{ df } & $\begin{array}{l}\% \text { GLA } \\
15 \text { DAF }\end{array}$ & $\begin{array}{l}\% \text { GLA } \\
30 \text { DAF }\end{array}$ & $\begin{array}{l}\% \text { GLA } \\
45 \text { DAF }\end{array}$ & $\begin{array}{c}\text { GLA at } \\
\text { flowering } \\
\left(10^{3} \mathrm{~cm}^{2}\right)\end{array}$ & $\begin{array}{l}\text { Days to } \\
\text { flowering }\end{array}$ \\
\hline & & \multicolumn{5}{|c|}{ Mean squares } \\
\hline Year & $\mathbf{1}$ & 800.3 & 3742.0 & 29212.9 & 3315.9 & 3719.5 \\
\hline Rep (Year) & 5 & 815.2 & 581.5 & 274.1 & 333.7 & 15.8 \\
\hline Block $($ Rep $\times$ Year $)$ & 53 & 140.6 & 189.3 & 186.8 & 61.1 & 8.5 \\
\hline Genotype & 71 & 443.1** & 814.6** & $1059.0 * *$ & $96.5 * *$ & $216.0 * *$ \\
\hline Genotype $\times$ Year & 71 & $99.1 * *$ & $167.9 * *$ & 77.3 & $39.7 * *$ & $55.7 * *$ \\
\hline Error & 302 & 41.7 & 73.5 & 66.3 & 18.0 & 3.5 \\
\hline Trial mean & & 76.0 & $\mathbf{5 3 . 0}$ & 30.6 & 1454 & 77 \\
\hline CV $(\%)$ & & 11.1 & 19.9 & 38.0 & 9.3 & 2.4 \\
\hline Heritability (entry mean) & & 0.78 & 0.79 & 0.83 & 0.70 & 0.74 \\
\hline
\end{tabular}

** Significant at $\boldsymbol{P}<\mathbf{0 . 0 1}$.

genotypes in grain yield in 1998-1999 were only marginally related to leaf area at flowering $(r=0.22, P<0.07)$ but were significantly related to time to flowering $(r=$ $-0.42, P<0.003)$. Clearly early flowering was the predominant factor in genotype yield differences in 19981999, rather than a greater potential yield level (as indicted by leaf area at flowering), as would be expected in a crop growing on limited stored soil moisture. Differences among genotypes in grain yield in 1999-2000 were not related to either early growth, as indicated by leaf area at flowering $(r=0.09, P>0.43)$, or to time to
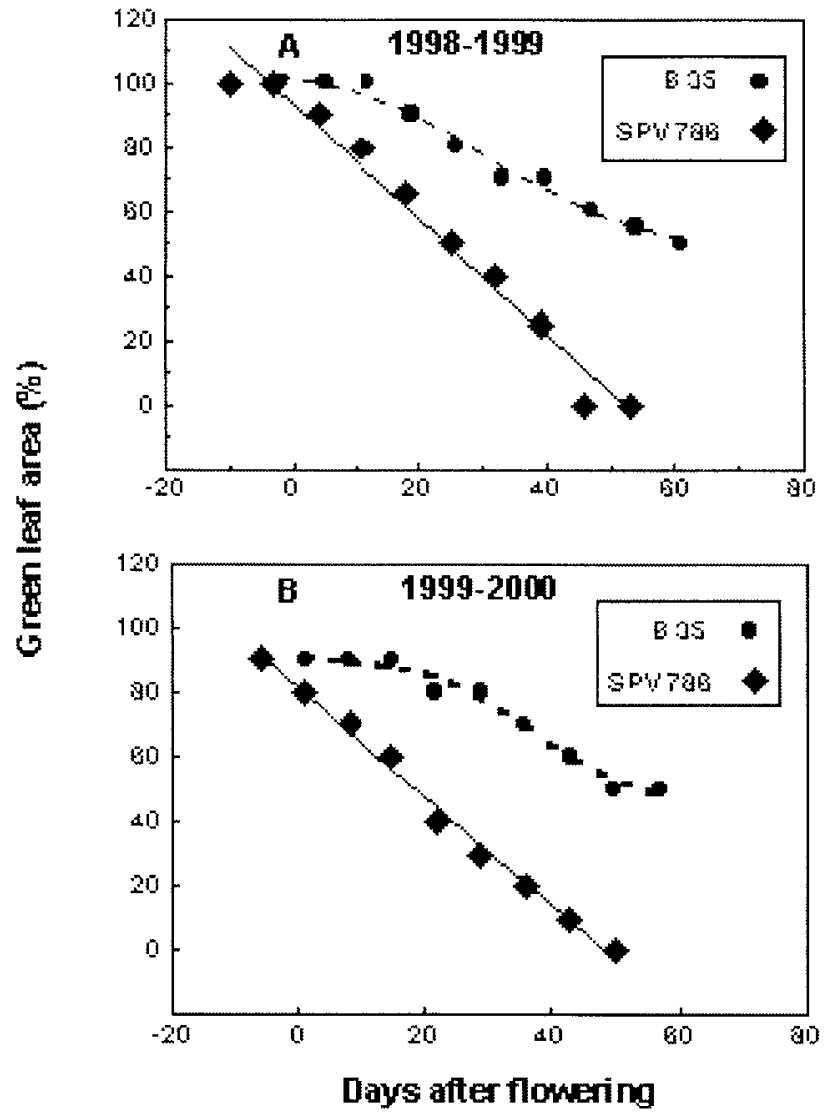

Fig. 2. Field percentage green leaf area in relation to days from flowering for B 35 (stay -green) and SPV 783 (senescent) genotypes in 1998-1999 (A) and 1999-2000 (B). Equations were fitted to these points to estimate percentage green leaf area for various times after flowering. flowering $(r=-0.11, P>0.36)$, however. Evidently, the milder stress in 1999-2000 resulted in less of a yield advantage attributable to early flowering.

\section{Leaf Senescence Patterns}

Leaf senescence patterns could be described either by a logistic or a linear curve (Fig. 2). Most stay-green lines, such as B 35, exhibited a delayed onset of senescence, and, in some cases, a slower rate of senescence, once leaf senescence began, than did the known senescent line SPV 786 (Fig. 2). The combined effect of differences in onset and rate of senescence often resulted in large differences among lines in \% GLA at maturity (Fig. 2). Differences in patterns of senescence are common in many species that exhibit stay green, even among genotypes that may retain same level of leaf area at maturity (Thomas and Howarth, 2000). For example, Borrell et al. (2000a), in a study of nine sorghum hybrids based on two different sources of stay green (B 35 and KS 19), reported that KS 19 hybrids had a delayed onset and reduced rate of senescence, whereas B 35 hybrids had only delayed onset of senescence. KS 19 hybrids had a smaller leaf area at flowering than the B 35 hybrids, however; so the green-leaf areas at maturity for both were similar. The nitrogen concentration in the green leaves of both the B 35 and KS 19 hybrids was also reported to be higher than in senescent hybrids at midgrain fill and maturity, yet this was associated with thicker leaves only in hybrids with the B 35 source (Borrell and Hammer, 2000).

To compare genotypic differences in pattern of senescence statistically, the estimated \% GLA (from the equations fitted to the field data) at 15,30 , and $45 \mathrm{DAF}$ for all plots were analyzed for effects of genotype and year $\times$ genotype (Table 2 ). By means of the three time estimates of \% GLA, it is possible to analyze genotype and genotype $\times$ year differences in time of onset of senescence (initial lag period in the logistic function), as well as in \% GLA at mid-grain filling and maturity. There were significant genotype differences in the estimated \% GLA at 15, 30, and 45 DAF (Table 2). The interaction of genotypes with years was significant for $\%$ GLA at 15 and 30 DAF only, indicating that interactions with year mainly affected the time of onset of stress, 
rather than the final \% GLA remaining at maturity. The heritability estimates of \% GLA, as determined in this experiment, were surprisingly high (0.78-0.80), and equivalent to heritability of days to flowering and green-leaf area at flowering (Table 2). Although \% GLA estimated in this experiment required very intensive sampling, it appeared to improve the estimates of heritability. This effort would seem justified for specific objectives, such as phenotyping mapping populations (where heritabilty is important for QTL detection), because of the advantages of markers in facilitating the incorporation of the stay-green trait in sorghum genotypes for drought-prone environments.

Differences among genotypes in \% GLA were significantly affected by time to flowering in 1998-1999. Laterflowering genotypes had a significantly lower \% GLA at $15 \mathrm{DAF}(r=-0.42, P<0.003)$, a similar \% GLA at $30 \mathrm{DAF}(r=-0.11, P>0.33)$, but a significantly higher \% GLA at 45 DAF $(r=0.43, P<0.001)$. Apparently, grain yields were more affected (directly) by the stress in later-flowering genotypes, and as a result, there was less translocation from the leaves. This reduced senescence rate ultimately resulted in a higher \% GLA at maturity in the late-flowering genotypes than in early flowering ones, despite the fact that senescence began at an earlier developmental stage in the case of the later flowering genotypes. This explanation is supported by a negative relationship between grain yield and \% GLA at $45 \operatorname{DAF}(r=-0.45, P<0.001)$, i.e., the less the yield, the greater the \% GLA, though there was a meaningful relationship at \% GLA at 30 DAF $(r=-0.22, P<$ 0.08 ). Thus, differences among genotypes in escape from stress, which result in differences in grain number or grain growth under grain filling stress, and, consequently, in the amount of nitrogen translocated from the leaves, affect leaf senescence in unanticipated ways. Clearly, comparisons of leaf senescence among genotypes with different flowering times, especially under severe stress, must be made with care.

In contrast, in 1999-2000, under a somewhat milder stress, there was no effect of time to flowering on \% GLA at $15 \mathrm{DAF}(r=0.04), 30 \mathrm{DAF}(r=0.03)$, or at $45 \mathrm{DAF}(r=0.03)$, or on grain yield $(r=-0.11, P>$ 0.35 ), despite the time-to-flowering range of $25 \mathrm{~d}$ among the 72 genotypes. Consequently, there were no significant correlations between \% GLA at any of the times of measurement and grain yield.

\section{Grouping of Genotypes on the Basis of Stay-Green Trait}

To classify the 72 genotypes by type and level of expression of stay green across the two years, clustering was done on the basis of six variables: \% GLA at 15, 30 , and $45 \mathrm{~d}$ after flowering in each of the years. This method allows for differences in response to the two years (i.e., genotype $\times$ year interactions) in both the time of onset and rate of senescence. The clustering procedure was truncated at five groups that retained $74 \%$ of the original variation in these traits (Fig. 3). Cluster 1 and Cluster 2 represented the stay-green geno- types, whereas Cluster 4 and Cluster 5 contained the most senescent genotypes (Table 1).

On the basis of combined data from the two years, Cluster 1 genotypes had a higher \% GLA at 15 DAF (delayed onset of senescence) than did Cluster 2 genotypes, but senesced at a greater rate thereafter, particularly between 30 and $45 \mathrm{DAF}$, to reach approximately the same \% GLA at 45 DAF as Cluster 2 genotypes (Table 1). There was, however, a major difference between the two stay-green clusters in their response to the two years. In 1998-1999, final mean \% GLA (45 DAF) was lower than that in 1999-2000. Consistent with the more severe stress in 1998-1999, Cluster 1 genotypes clearly delayed onset of senescence much more effectively than Cluster 2 genotypes. In contrast, in 19992000, Cluster 1 and Cluster 2 genotypes had similar patterns of senescence (Fig. 4). Cluster 1 and Cluster 2 genotypes differed significantly in mean time to flowering in both years (74 vs. $95 \mathrm{~d}$ in 1998-1999 and 71 vs. $81 \mathrm{~d}$ in 1999-2000). This means that Cluster 1 genotypes had two advantages over Cluster 2 genotypes: (i) a lower seasonal total transpiration because of a shorter growing season, and (ii) a less severe stress after flowering in years when the evaporative demand increased with time. Both of these advantages were likely factors in this experiment. In 1998-1999, both the preflowering (301 $\mathrm{mm})$ and postflowering $(288 \mathrm{~mm})$ cumulative evaporative demand, to which Cluster 1 genotypes were exposed, were considerably less than that to which Cluster 2 genotypes (417 $\mathrm{mm}$ preflowering and $342 \mathrm{~mm}$ postflowering) were exposed (Table 3 ). The advantages of early flowering in 1998-1999 were especially marked in the first $15 \mathrm{~d}$ of grain filling when leaf senescence begins: Cluster 1 genotypes were exposed to a cumulative evaporative demand of $79 \mathrm{~mm}$, compared with $103 \mathrm{~mm}$ for Cluster 2 genotypes (Table 3 ). In the less stressed year, the differences in cumulative evaporative demand between Cluster 1 and Cluster 2 genotypes were less marked in both the preflowering period $(353 \mathrm{~mm}$ for Cluster 1 vs. $399 \mathrm{~mm}$ for Cluster 2) and the grain-filling period ( $255 \mathrm{~mm}$ for Cluster 1 vs. $297 \mathrm{~mm}$ for Cluster 2; Table 3). Thus, the differences between Cluster 1 and Cluster 2 in 1998-1999 are likely to be largely a consequence of drought escape. In 1999-2000, where early flowering conferred less of an advantage, the senescence patterns of the two clusters were similar (Fig. 4). Therefore, Cluster 2 genotypes are likely to have the same level of per se nonsenescence, as do Cluster 1 genotypes, despite being grouped into different clusters on the basis of observed \% GLA.

Cluster 3, 4, and 5 genotypes had similar mean time to flowering in both years (78-81 d in 1998-1999 and 72-75 d in 1999-2000); therefore, comparisons among these clusters are not affected by differences in drought escape. Cluster 3 genotypes were similar to Cluster 4 genotypes in 1998-1999 (the more severely stressed year), and similar to Clusters 1 and 2 genotypes in 19992000 (the less severely stressed year; Fig. 4). The genotypes in Cluster 3 appear to have a moderate level of stay green, which was expressed under moderate stress 


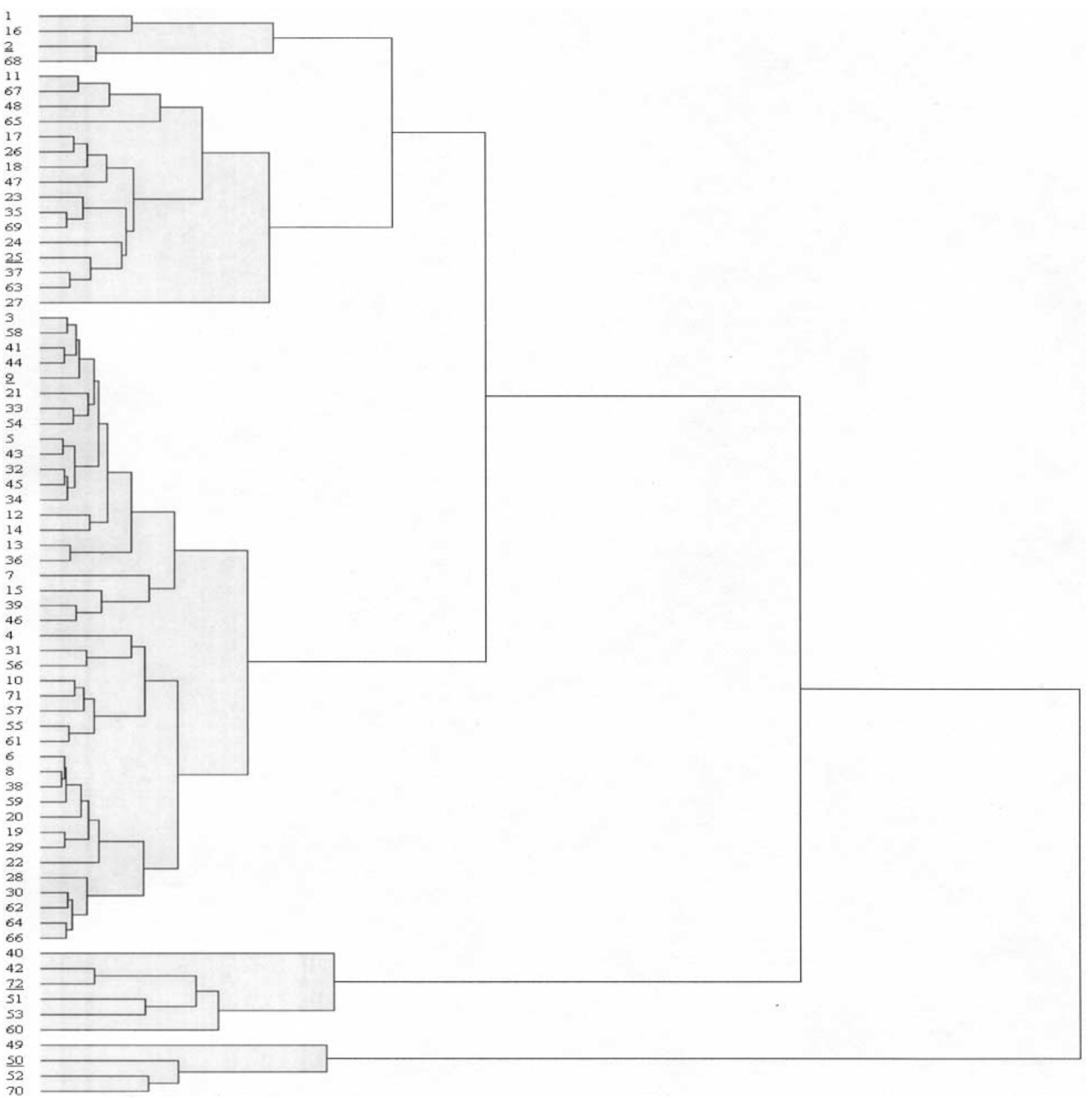

Fig. 3. Dendrogram of 72 stay-green sources, based on percentage green leaf area at 15, 30, and 45 d after flowering in both 1998-1999 and 1999-2000. Clustering was truncated at five clusters, which retained $74 \%$ of the initial variation in percent green leaf area. See Table 2 for pedigree information.

conditions. Their greater degree of senescence in the more severely stressed year of 1998-1999, despite the fact that they flowered earlier than the Cluster 2 genotypes, however, indicates that they are less useful as sources of the trait than genotypes in Cluster 1 or Cluster 2. They may be useful as parents for general breeding purposes in moderate stress environments, however. Cluster 4 and 5 genotypes were similar in their pattern of senescence although Cluster 4 genotypes maintained a higher \% GLA throughout the grain-filling period, especially under the more severe stress in 1998-1999 (Fig. 4).

The pattern of senescence in individual genotypes is influenced by both the time of onset and the rate of development of stress in an individual environment. It is, however, possible at least to understand qualitatively the effects of different times of onset of senescence and rates of senescence (because of environmental differences or drought escape) and to identify nonsenescent genotypes across different patterns of stress development. It is also evident that genotypes with intermediate levels of nonsenescence (such as those in Cluster 3 ) will be classified as more or less senescent, depending upon the pattern of stress development. This is also consistent with the hypothesis that there are more than one mechanism by which leaves stay green (Thomas and Howarth, 2000) which are likely controlled by different genes that, in turn, are triggered by the specific pattern of stress development (Dunwell, 2000). 


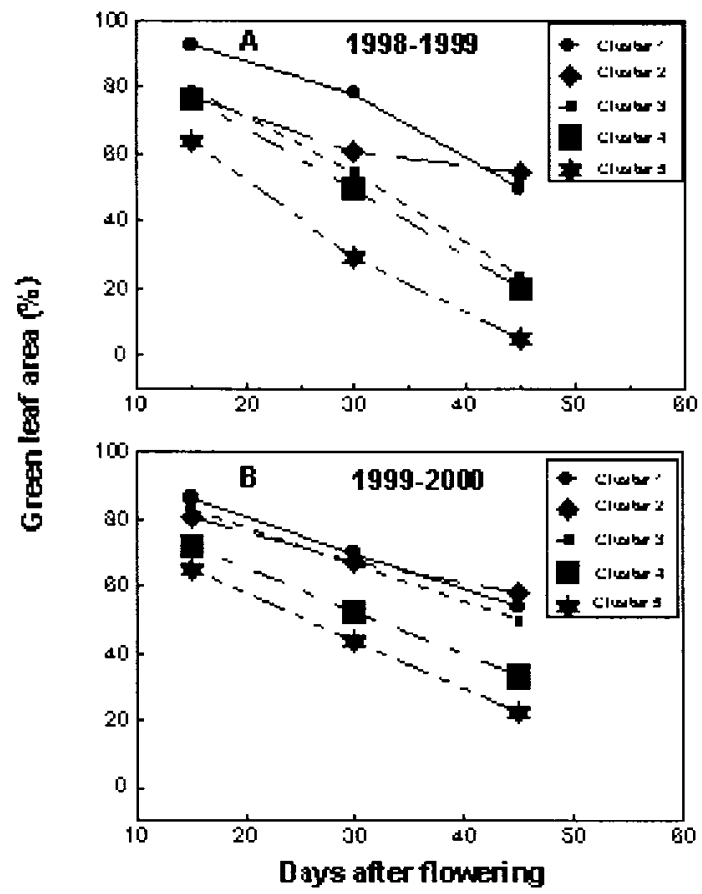

Fig. 4. Mean percentage green leaf area at 15, 30, and $45 \mathrm{~d}$ after flowering of the five stay-green clusters in 1998-1999 (A) and 19992000 (B). See Table 2 for details of the cluster composition and cluster means.

\section{Stay-Green Sources}

Cluster 1 genotypes included the two most widely used stay-green sources-B 35 and KS 19 (in the form of QL 10 and QL 27), which combined both stress escape and stay green (primarily by delayed onset of stress) in the post-rainy season in India (Table 1). Their drought escape is likely to be an artifact of the short daylength of November-December at ICRISAT (17 N), and may not be a major factor in longer day lengths in main growing seasons elsewhere. The other Cluster 1 genotype, IS 22380, is a landrace from Sudan that was classified as stay green (Van Oosterom et al., 1996). It also benefitted from early flowering caused by the short daylength, but had a marked delay in onset of senescence in both years (Table 2). The line may be worth evaluating further in other environments in which stay green is of value, as it is of a different biological race (caudatum) than either B 35 or KS 19.

Three of the four nonsenescent lines in Cluster 2 are ICRISAT breeding lines derived from the ICRISAT $\mathrm{B} / \mathrm{R}$ line multifactor resistance population (ICSP-2 B/R MFR); two of these trace back to the same $S_{2}$ line from the population (S2 407-1), and two of the lines also have E 36-1 in their pedigree, suggesting these lines may have conferred the stay-green trait. The multifactor resistance population includes both sources of stay green and resistance to charcoal rot (Dr. B.V.S. Reddy, ICRISAT, 2000, personal communication). E 36-1 is a recognized source of stay green (Van Oosterom et al., 1996), and has been widely used in the drought-breeding program at ICRISAT. E 36-1 itself, however, clustered with genotypes in Cluster 3, where its \% GLA at 45 DAF was approximately half of that of its derivatives under the
Table 3. Cumulative evaporative demand for pre- and post-flowering stages for Clusters 1, 2, and 3 (see Table 2). Data are from replicated field evaluations of 72 stay-green sources during the post-rainy seasons of 1998-1999 and 1999-2000 at ICRISAT, Patancheru, India.

\begin{tabular}{lccc}
\hline & \multicolumn{3}{c}{ Cumulative pan evaporation (mm) } \\
\cline { 2 - 4 } Year and growth period & Cluster 1 & Cluster 2 & Cluster 3 \\
\hline 1998-1999 & & & \\
Pre-flowering & 301 & 417 & 332 \\
Flowering to 15 DAF & 79 & 103 & 91 \\
16 DAF to 30 DAF & 98 & 118 & 103 \\
31 DAF to 45 DAF & 111 & 121 & 119 \\
Flowering to 45 DAF & 288 & 342 & 313 \\
1999-2000 & & & \\
Pre-flowering & 354 & 399 & 358 \\
Flowering to 15 DAF & 73 & 86 & 74 \\
16 DAF to 30 DAF & 89 & 92 & 89 \\
31 DAF to 45 DAF & 93 & 99 & 95 \\
Flowering to 45 DAF & 255 & 297 & 258 \\
\hline
\end{tabular}

more severe stress in 1998-1999, although it was nonsenescent when the stress development was more gradual in 1999-2000 (Table 1). The Cluster 2 line E36 × R $168 / 1$ is a deliberate stay-green selection from a cross between stay green and senescent (R 16) parents, so E36-1 would appear to transmit the trait to its progeny with adequate selection. The two senescent checks R16, and SPV 783 (Van Oosterom et al., 1996), appear in Cluster 5, as expected.

A small quantity of seed of these genotypes is available on request from the ICRISAT Genebank Curator. The seed request forms and other details are available on line at http://www.icrisat.org/text/research/grep/ homepage/grephomepage/mta.htm (verified November $12,2001)$.

\section{ACKNOWLEDGMENTS}

The authors thank Dr. B.V.S. Reddy, ICRISAT sorghum breeder for the identification and supply of seed of many of the lines used in this study, and Messrs. B Shivaiah and M. Kistaiah for their assistance in the collection of the field data.

\section{REFERENCES}

Borrell, A.K., F.R. Bidinger, and K. Sunitha. 1999. Stay-green associated with yield in recombinant inbred sorghum lines varying in rate of leaf senescence. Intl. Sorghum and Millets Newsl. 40:31-33.

Borrell, A.K., and G.L. Hammer. 2000. Nitrogen dynamics and the physiological basis of stay-green in sorghum. Crop Sci. 40:12951307.

Borrell, A.K., G.L. Hammer, and A.C.L. Douglas. 2000a. Does maintaining green leaf area in sorghum improve yield under drought? I. Leaf growth and senescence. Crop Sci. 40:1026-1037.

Borrell, A.K., G.L. Hammer, and R.O. Henzell. 2000b. Does maintaining green leaf area in sorghum improve yield under drought? II. Dry matter production and yield. Crop Sci. 40:1037-1048.

Borrell, A.K., Y.Z. Tao, and C.L. McIntyre. 2000c. Physiological basis, QTL and MAS of the stay-green drought resistance trait in grain sorghum. p. 142-146. In J.-M. Ribaut and D. Poland (ed.) Molecular approaches for the genetic improvement of cereals for stable production in water-limited environments. A strategic planning workshop held at CIMMYT, El Batan, Mexico. 21-25 June 1999. Mexico, CIMMYT.

Crasta, O.R., W.W. Xu, D.T. Rosenow, J.E. Mullet, and H.T. Nguyen 1999. Mapping of post-flowering drought resistance traits in grain sorghum: Association between QTLs influencing premature senescence and maturity. Mol. Gen. Genet. 262:579-588.

Dunwell, J.M. 2000. Transgenic approaches to crop improvement. J. Exp. Bot. 51:487-496. 
Henzell, R.G., R.L. Brengman, D.S. Fletcher, and A.N. McCosker. 1992. Relationships between yield and non-senescence (stay-green) in some grain sorghum hybrids grown under terminal drought stress. p. 355-358. In M.A. Foale et al. (ed.) Proc. of the Second Australian Sorghum Conference. Gatton, Australia. 4-6 Feb. 1992. Occasional Publication no. 68. Australian Inst. of Agric. Sci., Melbourne, Australia.

Henzell, R.G., R.L. Dodman, A.A. Done, R.L. Brengman, and R.E. Meyers. 1984. Loding, stalk rot and root rot in sorghum in Australia. p. 225-236. In L.K. Mughogho (ed.) Sorghum root and stalk rots: A critical review. Proc. Consultative Group Discussion of Research Needs and Strategies for Control of Sorghum Root and Stalk Rot Diseases. Bellagio, Italy. 27 Nov.-2 Dec. 1983. ICRISAT, Patancheru, A.P., India.

McBee, G.G. 1984. Relation of senescence, nonsenescence, and kernel maturity to carbohydrate metabolism in sorghum. p. 119-129. In L.K. Mughogho (ed.) Sorghum root and stalk rots: A critical review. Proc. Consultative Group Discussion of Fesearch Needs and Strategies for Control of Sorghum Root and Stalk Rot diseases, Bellagio, Italy. 27 Nov.-2 Dec. 1983. ICRISAT, Patancheru, A.P., India.

Mughogho, L.K., and S. Pande. 1984. Charcoal rot of sorghum. p. 11-24. In L.K. Mughogho (ed.) Sorghum root and stalk rots: A critical review. Proc. Consult. Group Discussion on Research Needs and Strategies for Control of Sorghum Root and Stalk Rot Diseases, Bellagio, Italy. 27 Nov.-2 Dec. 1983. ICRISAT, Patancheru, A.P., India.

Rosenow, D.T., and L.E. Clark. 1981. Drought tolerance in sorghum. p. 18-31. In H.D. Loden and D. Wilkinson (ed.) Proc. 36th Annu. Corn and Sorghum Industry Res. Conf. Chicago, IL. 9-11 Dec. 1981. Am. Seed Trade Assoc., Washington, DC.
Rosenow, D.T., G. Ejeta, L.E. Clark, M.L. Gilbert, R.G. Henzell, A.K. Borrell, and R.C. Muchow. 1996. Breeding for pre- and postflowering drought stress resistance in sorghum. p. 400-411. In D.T. Rosenow and J.M. Yohe (ed.) Proceedings of the International Conference on Genetic Improvement of Sorghum and Pearl Millet, Lubbock, TX. 22-27 Sept. 1996. INTSORMIL, Lubbock, TX, and ICRISAT, India

Rosenow, D.T., J.W. Johnson, R.A. Fredriksen, and F.R. Miller. 1977. Relationship of non senescence to lodging and charcoal rot in sorghum. p. 69. In Agron. Abstr. ASA, Madison, WI.

Rosenow, D.T., J.E. Quisenberry, C.W. Wendt, and L.E. Clark. 1983. Drought tolerant sorghum and cotton germplasm. Agric. Water Manag. 7:207-222.

SAS Institute Inc. 1996. SAS/STAT user's guide. Release 6.12. SAS Institute, Inc., Cary, NC.

Sivakumar, M.V.K., N. Seetharama, S. Singh, and F.R. Bidinger. 1979. Water relations, growth and dry matter accumulation of sorghum under post-rainy season conditions. Agron. J. 71:843-847.

Thomas, H., and C.M. Smart. 1993. Crops that stay green. Ann. Appl. Biol. 123:193-219.

Thomas, H., and C.J. Howarth. 2000. Five ways to stay green. J. Exp. Bot. 51:329-337.

Van Oosterom, E.J., R. Jayachandran, and F.R. Bidinger. 1996. Diallel analysis of the stay-green trait and its components in sorghum. Crop Sci. 36:549-555.

Xu, W.W., P.K. Subudhi, O.R. Crasta, D.T. Rosenow, J.E. Mullet, and H.T. Nguyen. 2000. Molecular mapping of QTLs conferring stay-green in grain sorghum (Sorghum bicolor L. Moench). Genome 43:461-469. 